\title{
Removal of 4-chlorophenol from aqueous solution by granular activated carbon/nanoscale zero valent iron based on Response Surface Modeling
}

\author{
Monireh Majlesi ${ }^{1,2}$, Yalda Hashempour ${ }^{2 *}$ \\ ${ }^{1}$ Shahid Beheshti University of Medical Sciences, Iran \\ Environmental and Occupational Hazards Control Research Center \\ ${ }^{2}$ Shahid Beheshti University of Medical Sciences, Iran \\ Department of Environmental Health Engineering, School of Public Health, Student Research Committee \\ *Corresponding author's e-mail: yalda.hashempour@yahoo.com
}

Keywords: response surface methodology, 4-chlorophenol, NZVI/AC.

\begin{abstract}
The phenolic compounds are known as priority pollutants, even in low concentrations, as a result of their toxicity and non-biodegradability. For this reason, strict standards have been established for them. In addition, chlorophenols are placed in the 38th to 43th in highest priority order of toxic pollutants. As a consequence, contaminated water or wastewaters with phenolic compounds have to be treated before discharging into the receiving water. In this study, Response Surface Methodology (RSM) has been used in order to optimize the effect of main operational variables responsible for the higher 4-chlorophenol removal by Activated Carbon-Supported Nanoscale Zero Valent Iron (AC/NZVI). A Box-Behnken factorial Design (BBD) with three levels was applied to optimize the initial concentration, time, $\mathrm{pH}$, and adsorbent dose. The characterization of adsorbents was conducted by using SEM-EDS and XRD analyses. Furthermore, the adsorption isotherm and kinetics of 4-chlorophenol on $\mathrm{AC}$ and $\mathrm{AC} / \mathrm{NZVI}$ under various conditions were studied. The model anticipated $100 \%$ removal efficiency for $\mathrm{AC} / \mathrm{NZVI}$ at the optimum concentration (5.48 $\mathrm{mg}$ 4-chlorophenol/L), $\mathrm{pH}(5.44)$, contact time (44.7 min) and dose $(0.65 \mathrm{~g} / \mathrm{L})$. Analysis of the response surface quadratic model signified that the experiments are accurate and the model is highly significant. Moreover, the synthetic adsorbent is highly efficient in removing of 4-chlorophenol.
\end{abstract}

\section{Nomenclature}

RSM Response surface methodology

BBD Box-Behnken factorial design

AC Activated carbon

NZVI Nano zero-valent iron

SEM scanning electron microscope

EDS electron dispersion spectrometer

XRD x-ray diffraction

PEG polyethylene glycol

$\mathbf{q}_{\mathrm{e}}$ the amount of 4-CP adsorbed (mg $\left.\mathrm{l}^{-1}\right)$ at equilibrium time

$\mathbf{q}_{\mathrm{t}}$ the amount of 4-CP adsorbed ( $\left.\mathrm{mg} \mathrm{l}^{-1}\right)$ at any time $\mathrm{t}$

V volume oof the 4-CP solution

$\mathbf{C}_{0} \quad$ initial 4-CP concentration in solution $\left(\mathrm{mg} \mathrm{l}^{-1}\right)$

$\mathbf{C}_{\mathrm{e}}$ equilibrium 4-CP concentration $\left(\mathrm{mg} \mathrm{l}^{-1}\right)$

$\mathrm{m}$ mass of dry adsorbate added $(\mathrm{g})$

$\mathbf{R}$ the removal efficiency of 4-CP (\%)

$\mathbf{C}_{\mathrm{t}}$ final 4-CP concentration in solution $\left(\mathrm{mg} \mathrm{l}^{-1}\right)$

$\mathbf{X}_{\mathbf{t}_{j}}$ the coded value of an independent variable

$\mathbf{X}_{\mathrm{i}}$ the real value of an independent variable

$\mathbf{X}_{\mathbf{0}}$ the real value of an independent variable at the center point

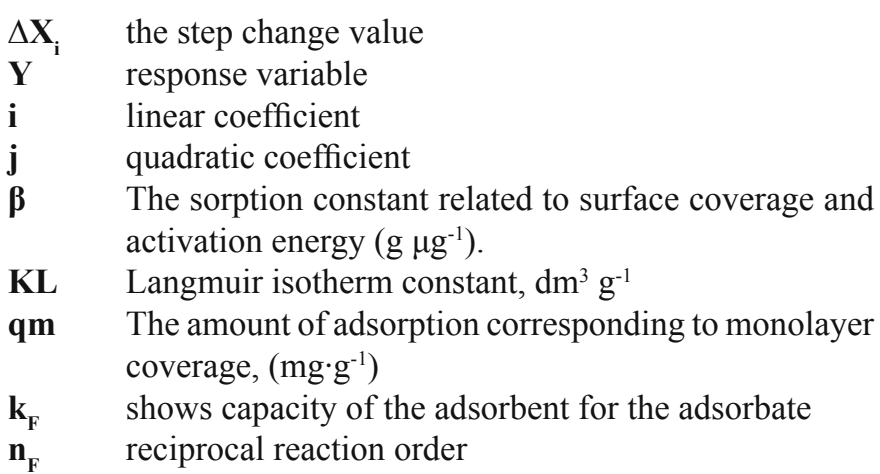

\section{Introduction}

Phenolic compounds enter the environment at different concentrations from large number of industries such as petrochemical industry, coal industry, rubber, paper, plastics, and oil refineries (Tepe and Dursun 2008, Bayramoğlu and Arica 2008). In addition, those compounds can be produced by the degradation of chlorinated pesticides into the environment and in the presence of chlorine, which is produced during the burning of organic material (Navarro et al. 2008, Sądej et al. 2016). The phenol features, such 
as solubility in water and their stability in the environment, could result in the compounds lasting for a long time in the environment and water sources are able to transfer them to long distances (Rappoport 2004).

By replacing chlorine with hydrogen number 4 in the benzene ring of phenol, 4-chlorophenol (4-CP) or para-chlorophenol $\left(\mathrm{C}_{6} \mathrm{H}_{5} \mathrm{ClO}\right)$ as a phenolic compound is produced. In its normal state, the organic matter is a slightly acidic solid of soil color with the melting point, boiling point, specific gravity, and chemical molecular weight of 43.2, 218.5, 1.265, and $128.56 \mathrm{gr} / \mathrm{mol}$, respectively (Rappoport 2004). The compound enters the environment through vast verities of sources and has several side effects. The toxic effects of these compounds on humans consist of vomiting, difficulty in swallowing, loss of appetite, kidney and liver damage and mental damages. The long-term exposure to these compounds contributes to headache, fatigue, irritability, liver and kidney impairment, muscle weakness, nausea and ultimately coma (1989). These compounds are known as priority pollutants, even in low concentrations, as a result of their toxicity and non-biodegradability. For this reason, strict standards have been established for them (Bayramoglu et al. 2009).

The maximum permissible concentration of phenolic compounds in drinking water is 0.5 micrograms per liter based on the European Union standard and 1 microgram per liter based on the America standard (Tseng et al. 2011). In addition, chlorophenols are placed in the 38th to 43th in highest priority of toxic pollutants, in accordance with the division of Europe Committee for water pollution (Eckenfelder 1989). As a consequence, contaminated water or wastewaters with phenolic compounds have to be treated before discharging into the receiving water.

Biological treatment, solvent extraction, burning, air stripping, chemical oxidation, and electrochemical methods are perceived as the most important methods for the removal of phenol and phenolic compounds from wastewater ( $\mathrm{Ra}$ et al. 2008, Rodríguez 2003). The presence of chlorine in the chlorophenol leads to the resistance of those compounds in the biodegradation process (Handbook 1998). Problems such as high cost, low efficiency and the production of toxic and hazardous substances are limiting factors when using some of those methods. Among the physico-chemical processes, absorption has been extensively studied ( $\mathrm{Wu}$ and $\mathrm{Yu} 2007$, Akar et al. 2008).

Adsorption is regarded as one of the most significant techniques for the treatment of domestic and industrial wastewater. It is a process in which molecules in a solution are drawn and accumulate to the internal surfaces of an adsorbent material. The process is simple, economic, fast and do not involve any filtration and chemical materials (Kassaee et al. 2011). Many adsorbents are used for the removal of phenol and chlorophenols in wastewater (Bayramoglu et al. 2009). Activated carbon is perceived as one of the most common. This adsorbent has a high capacity to remove organic contaminants, macro molecules, color, taste and odor (Wu et al. 2011). The activated carbons are modified in different ways, including their staining with iron, which can enhance its absorption capacity.

Iron is one of the metals that can be found in profuse amounts on the earth. Zero-valent iron is a type of iron which has a strong reducing element (Moradi et al. 2016). Compared to Zero-Valent Iron (ZVI), NZVI is more suitable for use since it has a higher specific surface area and reactivity (Kassaee et al. 2011, Mangal et al. 2013). On the other hand, zero-valent iron nanoparticles are widely used to remove organic compounds (Kassaee et al. 2011), chromium 6 valent (Ponder et al. 2000), herbicides (Joo et al. 2004), aromatics (Choe et al. 2001), and arsenic (Kanel et al. 2005). The use of a support, like activated carbon, does have suitable porosity for absorption of 4-CP from water and prevents the agglomeration of iron and therefore presents a higher specific surface area and surface charge of iron to the aqueous stream (Ponder et al. 2000). The characteristic contributes to extreme absorption of organic substances and heavy metals (Lai and Chen 2001, Cheng et al. 2005).

In this study, NZVI/AC were selected to carry out research on the 4-CP adsorption performance from the aqueous solution. In order to optimize the 4-CP adsorption onto AC/NZVIAC/NZVI, the design experiment, one of the statistical and mathematical softwares, was used (Asghar et al. 2014).

\section{Materials and methods}

\section{Chemicals and water sample}

In this study, used commercial AC was supplied by Merck. For synthesizing AC/NZVI, the following chemicals were needed: Iron (II) Sulfate Heptahydrate $\left(\mathrm{FeSO}_{4} \cdot 7 \mathrm{H}_{2} \mathrm{O}\right)$, potassium borohydride $\left(\mathrm{KBH}_{4}\right)$, polyethylene glycol (PEG) and ethanol $\left(\mathrm{C}_{2} \mathrm{H}_{5} \mathrm{OH}, 99.7 \%\right.$, v/v). A 4-CP stock solution of $1000 \mathrm{mg} / \mathrm{L}$ was prepared according to the standard method (Rice et al. 2012) and stored in a refrigerator at $4^{\circ} \mathrm{C}$ before being used. All working solutions were prepared by diluting the stock solution.

\section{Preparation of NZVI/AC}

The commercial AC was soaked in 5\% hydrochloric acid for $24 \mathrm{~h}$, then washed with deionized water until the water $\mathrm{pH}$ was stable $(\mathrm{pH}=6.52-6.70)$. After drying for $24 \mathrm{~h}$ at $105^{\circ} \mathrm{C}, \mathrm{AC}$ was used as a support for NZVI particle. The NZVI can be synthesized according to reference (S.R. Kanel et al. 2005) by the following reaction:

$$
\mathrm{Fe}^{2+}+2 \mathrm{BH}_{4}^{-}+6 \mathrm{H}_{2} \mathrm{O} \rightarrow \mathrm{Fe}^{0} \downarrow+2 \mathrm{~B}(\mathrm{OH})_{3}+7 \mathrm{H}_{2} \uparrow
$$

The procedure is described as follows: (1) $0.07 \mathrm{M}$ of iron solution was prepared by dissolving $\mathrm{FeSO}_{4} .7 \mathrm{H}_{2} \mathrm{O}$ in $100 \mathrm{~mL}$ of ethanol water (ethanol $/$ water $=3 / 7, \mathrm{v} / \mathrm{v}$ ) with addition of $0.5 \mathrm{~g}$ of PEG as surfactant, (2) $50 \mathrm{~mL}$ of $\mathrm{KBH}_{4}$ reductant was added dropwise $(2 \mathrm{~mL} / \mathrm{min})$ to a solution containing $\mathrm{AC}(4 \mathrm{~g})$ and $\mathrm{FeSO} 4.7 \mathrm{H}_{2} \mathrm{O}$ under vigorous magnetic stirring, (3) the solution was shaken for another $30 \mathrm{~min}$, (4) after addition of $\mathrm{KBH}_{4}$ it was completed, (5) the NZVI/AC formed was filtered and alternately rinsed with ethanol and three times each. Fig. 1 shows a schematic diagram for synthesis of NZVI/AC.

\section{General Characteristics of NZVI/AC}

The morphological properties of AC/NZVI were observed with a scanning electron microscope (SEM, TESCAN Vega Model). Localized AC/NZVI analyses from chosen regions were obtained with an INCA electron dispersion spectrometer (EDS) in conjunction with SEM. The crystal structure and crystallinity of the composites were examined by $\mathrm{x}$-ray diffraction (XRD). 


\section{Adsorption of 4-CP Experiments}

The adsorption behavior of 4-CP by AC/NZVI was investigated using a batch study. The effect of various parameters such as initial concentration of 4-CP, $\mathrm{pH}$, contact time, adsorbent dose, and type of adsorbent were evaluated. The adsorption experiments were performed in $250 \mathrm{ml}$ beakers by mixing $100 \mathrm{ml}$ of the desired 4-CP solution. The mixture was shacked at $200 \mathrm{rpm}$ for the desired time. All the experiments were performed at a constant temperature of $25 \pm 1^{\circ} \mathrm{C}$. The mixture was then filtered through $0.45 \mu$ and the remaining 4-CP in the supernatant solution was determined by measuring the absorbance at the maximum wavelength of $500 \mathrm{~nm}$ using a spectrophotometer (DR5000). Finally, the amount of 4-CP adsorbed on the AC/NZVI was calculated according to Equation 2 (H.-m. Cai et al. 2015):

$$
q_{e}=\frac{V\left(C_{0}-C_{e}\right)}{m}
$$

The removal efficiency of 4-CP was calculated according to Equation 3 (Q. Qin et al. 2011):

$$
R, \%=\frac{\left(C_{0}-C_{t}\right)}{C_{0}}
$$

\section{Experimental design}

4-CP removal was optimized by using the BBD. The number of experiments is noticeably reduced by this software (A. Jafari et al. 2014). More importantly, the optimization and modeling of 4-CP adsorption were performed by AC/NZVI using a BBD. Some studies demonstrated that RSM based on BBD has been used in different applications of environmental engineering, including the removal of mercury (Fakhri 2015), cadmium (Souza et al. 2005), fluoride (Mourabet et al. 2012), surfactants (Michaux et al. 2013) etc.

This design consists of three levels (coded as $-1,0$, and +1 ). The complete design consisted of 60 runs and these were performed in duplicate to optimize the levels of selected variables (initial concentration of 4-CP, $\mathrm{pH}$, contact time, adsorbent dose, and type of adsorbent). For statistical calculations, the five independent variables were designated as $\mathrm{X}_{1}, \mathrm{X}_{2}, \mathrm{X}_{3}, \mathrm{X}_{4}$ and $\mathrm{X}_{5}$, respectively, and were coded according to the following equation (Yazdanbakhsh and Hashempour 2015, Doddapaneni et al. 2007, Moradi et al. 2016):

$$
X_{j}=\frac{X_{i}-X_{0}}{\Delta X_{i}}
$$

The lowest and highest levels of the variables were 4-CP concentration 5 and 50, pH 3 and 9, time 1 and 60 minute, adsorbent dose 0.5 and $1.5 \mathrm{~g} / \mathrm{L}$, and type of adsorbent was AC and NZVI/AC (see table 1).

The 4-CP removal efficiency was multiply regressed as follows:

$$
Y=\beta_{0}+\sum \beta_{i} X_{i}+\sum \beta_{i i} X_{i}^{2}+\sum \beta_{i j} X_{i} X_{j}
$$

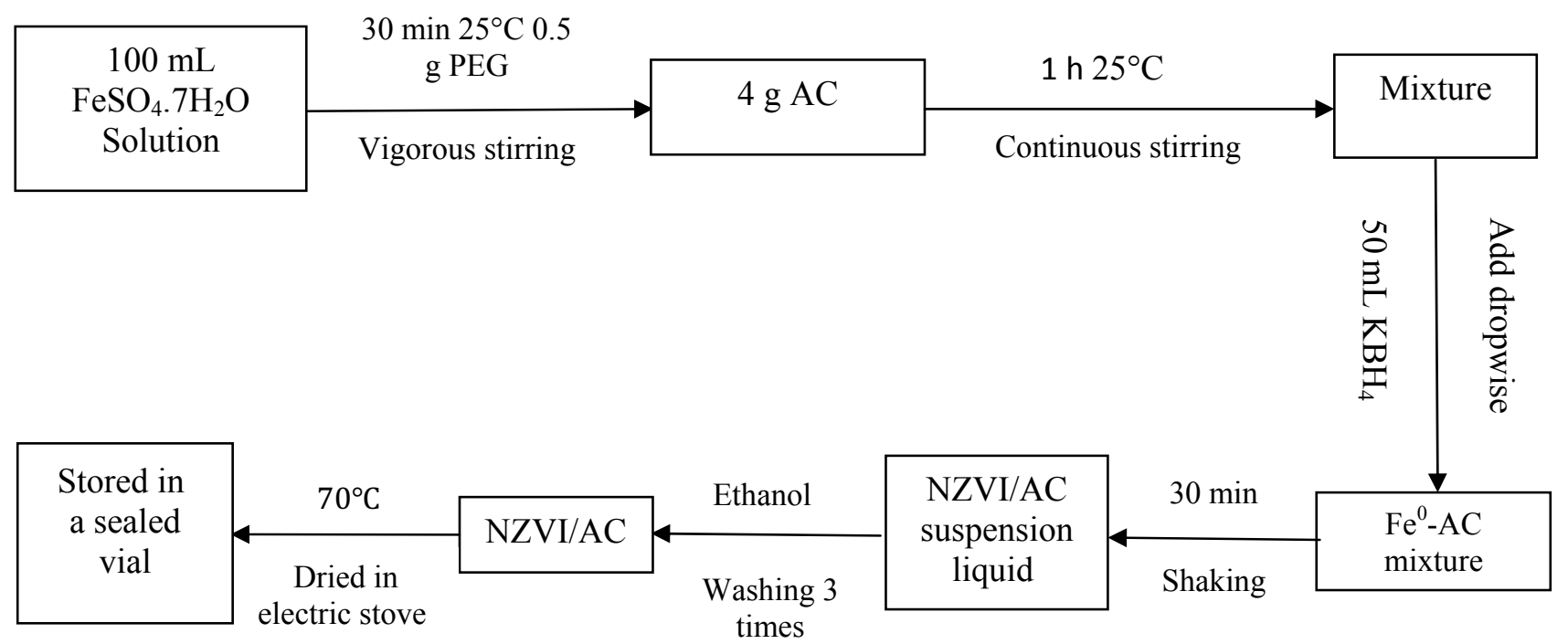

Fig. 1. The schematic diagram for synthesis of NZVI/AC

Table 1. Independent variable and their coded levels to central composite design

\begin{tabular}{|c|c|c|c|c|}
\hline Name & Units & $\mathbf{- 1}$ & $\mathbf{0}$ & $\mathbf{+ 1}$ \\
\hline Initial Concentration of 4-CP & $\mathrm{mg} \mathrm{L}^{-1}$ & 5 & 27.5 & 50 \\
\hline $\mathrm{pH}$ & - & 3 & 6 & 9 \\
\hline Contact Time & minute & 1 & 30.5 & 60 \\
\hline Adsorbent Dose & $\mathrm{g}$ & 0.5 & 1 & 1.5 \\
\hline
\end{tabular}


The accuracy and fitness of the above model were evaluated by $\mathrm{R}^{2}$ and $\mathrm{F}$ value. The BBD matrix is shown in Table 2. The predicted values for 4-CP removal were gained by applying a quadratic model (Design Expert software version 7, free trial, Stat ease, USA). The optimum values of the variable factors for 4-CP removal were obtained by solving the regression equation, and by analyzing the response surface contour. The goal fixed for the 4-CP removal was maximum 4-CP removal. Fig. 2 shows the step-by-step process for optimizing 4-CP removal.

Table 2. Box-Behnken design matrix in coded terms along with experimental and predicted values for 4-CP removal

\begin{tabular}{|c|c|c|c|c|c|c|c|}
\hline \multirow{2}{*}{ Runs } & \multicolumn{5}{|c|}{ Independent variables (coded) } & \multicolumn{2}{|c|}{ 4-CP removal $(\%)$} \\
\hline & $X_{1}$ & $\mathrm{X}_{2}$ & $\mathrm{X}_{3}$ & $X_{4}$ & $X_{5}$ & Experimental & Predicted \\
\hline 1 & 0 & 0 & 0 & 0 & $A C$ & 45.94 & 46.58 \\
\hline 2 & 0 & 0 & 0 & 0 & $\mathrm{NZVI/AC}$ & 88.84 & 88.20 \\
\hline 3 & 0 & 0 & 1 & -1 & $\mathrm{NZVI/AC}$ & 87.21 & 87.47 \\
\hline 4 & 0 & 0 & -1 & -1 & $\mathrm{NZVI/AC}$ & 62.78 & 62.34 \\
\hline 5 & 0 & 0 & 1 & -1 & $\mathrm{NZVI/AC}$ & 100 & 98.68 \\
\hline 6 & -1 & 1 & 0 & 0 & $\mathrm{NZVI/AC}$ & 100 & 100 \\
\hline 7 & 0 & 0 & 1 & -1 & $A C$ & 42.33 & 42.52 \\
\hline 8 & 1 & 1 & 0 & 0 & $\mathrm{NZVI/AC}$ & 57.2 & 58.86 \\
\hline 9 & -1 & 1 & 0 & 0 & $A C$ & 43.5 & 42.30 \\
\hline 10 & 0 & 0 & 0 & 0 & $\mathrm{NZVI} / \mathrm{AC}$ & 88.84 & 88.20 \\
\hline 11 & 0 & 0 & -1 & -1 & $A C$ & 23.39 & 24.05 \\
\hline 12 & 0 & 0 & 1 & -1 & $A C$ & 50.44 & 51.53 \\
\hline 13 & 0 & 0 & 0 & 0 & $A C$ & 45.94 & 46.58 \\
\hline 14 & 0 & 0 & -1 & -1 & $\mathrm{NZVI/AC}$ & 50.35 & 52.37 \\
\hline 15 & 0 & 0 & -1 & -1 & $A C$ & 17.41 & 16.28 \\
\hline 16 & -1 & 1 & 0 & 0 & $\mathrm{NZVI/AC}$ & 87.29 & 85.49 \\
\hline 17 & 1 & 1 & 0 & 0 & $A C$ & 21.6 & 21.00 \\
\hline 18 & -1 & 1 & 0 & 0 & $A C$ & 56.1 & 55.15 \\
\hline 19 & 1 & 1 & 0 & 0 & $A C$ & 48.77 & 52.98 \\
\hline 20 & 1 & 1 & 0 & 0 & $\mathrm{NZVI/AC}$ & 99.57 & 96.03 \\
\hline 21 & 1 & 0 & 0 & -1 & $\mathrm{NZVI} / \mathrm{AC}$ & 85.79 & 86.99 \\
\hline 22 & 0 & 1 & 1 & 0 & $\mathrm{NZVI} / \mathrm{AC}$ & 100 & 100 \\
\hline 23 & 0 & 1 & -1 & 0 & $A C$ & 28.25 & 26.90 \\
\hline 24 & 0 & 0 & 0 & 0 & $A C$ & 45.94 & 46.58 \\
\hline 25 & 0 & 1 & -1 & 0 & $\mathrm{NZVI} / \mathrm{AC}$ & 67 & 66.69 \\
\hline 26 & 0 & 1 & -1 & 0 & $A C$ & 10.44 & 7.88 \\
\hline 27 & 0 & 0 & 0 & 0 & $\mathrm{NZVI} / \mathrm{AC}$ & 88.84 & 88.20 \\
\hline 28 & 0 & 1 & 1 & 0 & $A C$ & 55.06 & 55.68 \\
\hline 29 & -1 & 0 & 0 & -1 & $A C$ & 51.2 & 50.29 \\
\hline 30 & 0 & 1 & 1 & 0 & $\mathrm{NZVI} / \mathrm{AC}$ & 76.43 & 76.30 \\
\hline 31 & 10 & 0 & 0 & -1 & $A C$ & 34.03 & 34.10 \\
\hline 32 & 0 & 1 & 1 & 0 & $A C$ & 32 & 32.85 \\
\hline 33 & -1 & 0 & 0 & -1 & $\mathrm{NZVI/AC}$ & 91.93 & 91.96 \\
\hline 34 & -1 & 0 & 0 & -1 & $A C$ & 57.48 & 55.72 \\
\hline 35 & 1 & 0 & 0 & -1 & $\mathrm{NZVI} / \mathrm{AC}$ & 72.29 & 73.45 \\
\hline 36 & -1 & 0 & 0 & -1 & $\mathrm{NZVI/AC}$ & 100 & 99.60 \\
\hline 37 & 1 & 0 & 0 & -1 & $A C$ & 46.68 & 45.44 \\
\hline 38 & 0 & 1 & -1 & 0 & $\mathrm{NZVI/AC}$ & 45.75 & 42.48 \\
\hline 39 & 0 & 0 & 0 & 0 & $\mathrm{NZVI/AC}$ & 88.84 & 88.20 \\
\hline 40 & 0 & 0 & 0 & 0 & $A C$ & 45.94 & 46.58 \\
\hline 41 & 0 & 1 & 0 & -1 & $\mathrm{NZVI/AC}$ & 100 & 96.40 \\
\hline 42 & 0 & 0 & 0 & 0 & $\mathrm{NZVI} / \mathrm{AC}$ & 88.84 & 88.20 \\
\hline
\end{tabular}




\begin{tabular}{|c|c|c|c|c|c|c|c|}
\hline 43 & 0 & 0 & 0 & 0 & AC & 45.94 & 46.58 \\
\hline 44 & 1 & 0 & 1 & 0 & NZVI/AC & 85.59 & 84.62 \\
\hline 45 & 0 & 1 & 0 & -1 & AC & 52.4 & 53.28 \\
\hline 46 & 1 & 0 & 1 & 0 & AC & 43.28 & 39.74 \\
\hline 47 & 0 & 1 & 0 & -1 & NZVI/AC & 63.25 & 64.78 \\
\hline 48 & 0 & 1 & 0 & -1 & NZVI/AC & 100 & 100 \\
\hline 49 & 0 & 1 & 0 & -1 & AC & 27.34 & 26.86 \\
\hline 50 & -1 & 0 & -1 & 0 & NZVI/AC & 61.84 & 64.45 \\
\hline 51 & 0 & 0 & 0 & 0 & NZVI/AC & 88.84 & 88.20 \\
\hline 52 & -1 & 0 & 1 & 0 & NZVI/AC & 100 & 80 \\
\hline 53 & 0 & 1 & 0 & -1 & NZVI/AC & 23.96 & 80.88 \\
\hline 54 & -1 & 0 & -1 & 0 & AC & 13.04 & 26.11 \\
\hline 55 & 1 & 0 & -1 & 0 & AC & 38.64 & 42.92 \\
\hline 56 & 0 & 1 & 0 & -1 & AC & 30.76 \\
\hline 57 & -1 & 0 & 1 & 0 & AC & 54.55 & 53.00 \\
\hline 58 & 1 & 0 & -1 & 0 & NZVI/AC & 47.23 & 48.94 \\
\hline 59 & 0 & 0 & 0 & 0 & AC & 45.94 & 46.58 \\
\hline 60 & 0 & 1 & 0 & -1 & AC & 58.42 & 56.16 \\
\hline
\end{tabular}

$\mathrm{X}_{1}=4-\mathrm{CP}$ concentration, $\mathrm{X}_{2}=\mathrm{pH}, \mathrm{X}_{3}=$ Time, $\mathrm{X}_{4}$ =adsorbent dose and $\mathrm{X}_{5}=$ Type of adsorbent

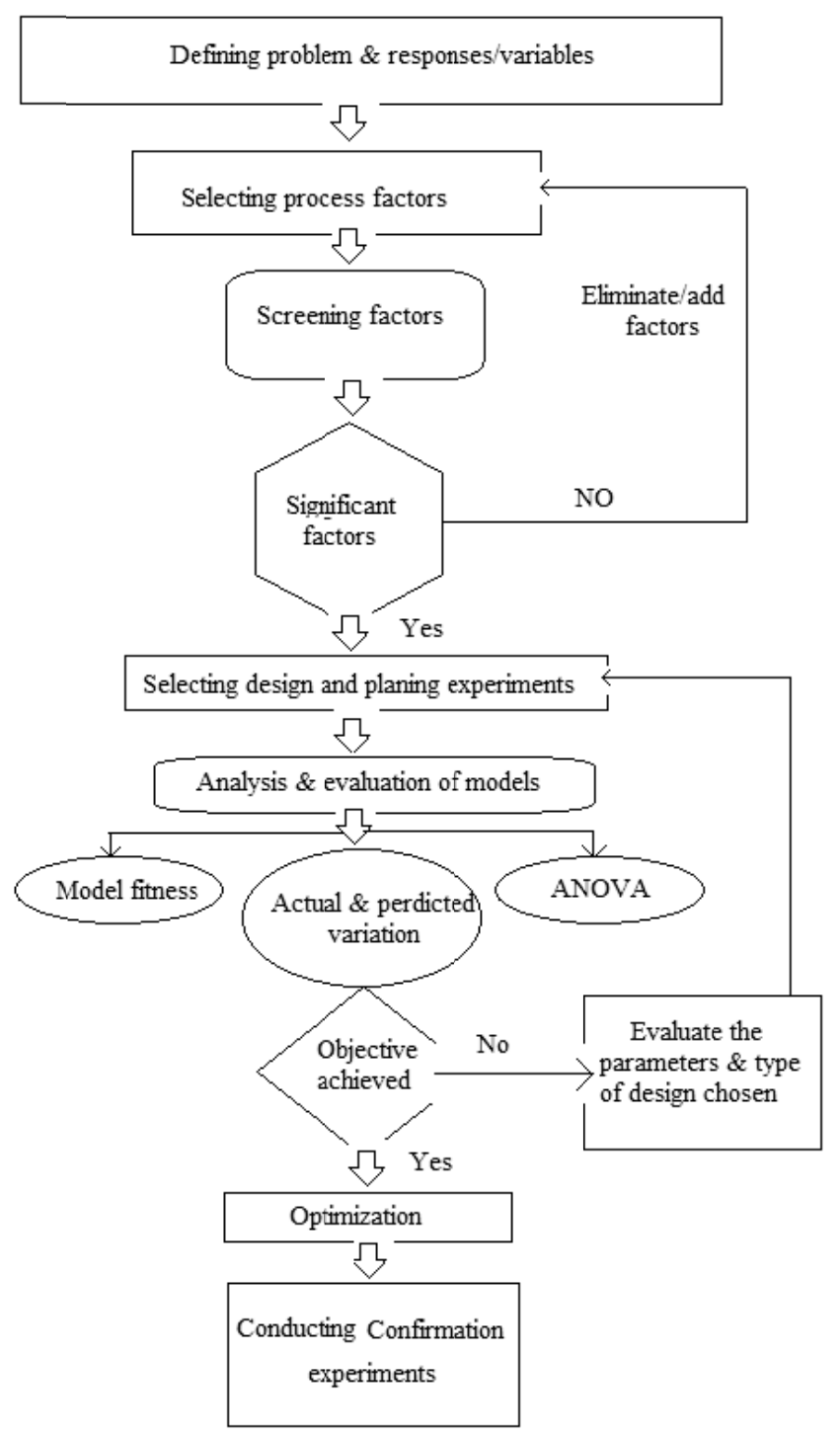

Fig. 2. Flowchart for optimization of 4-CP removal on the NZVI/AC with BBD method (Asghar et al. 2014) 


\section{Isotherm and kinetics study of NZVI/AC}

The adsorption isotherms were examined by the optimum condition of AC/NZVI dose (e.g. $0.65 \mathrm{~g} \mathrm{~L}^{-1}$ ), pH (e.g. 5.44), and initial 4-CP concentration was varied from 5 to $50 \mathrm{mg} \mathrm{L}^{-1}$ with the total volume of $100 \mathrm{~mL}$ in a $250 \mathrm{~mL}$ Erlenmeyer flask. The adsorption kinetic experiments were performed for $360 \mathrm{~min}$ to ensure that the 4-CP adsorption onto the adsorbent reached the equilibrium. After the period of contact time (360 min), the solution was filtered through $0.45 \mu$ for separating the adsorbent particles. Finally, the residual 4-CP concentration was analyzed. To determine the relationship between equilibrium capacity and equilibrium concentration, the isotherm models were used such as Langmuir (I, II, III, and IV types), and Freundlich. The empirical formula of the used isotherm models is shown in Table 3.

Adsorption kinetics is used to predict the rate of adsorption and adsorption mechanisms. In our study, the two types of kinetic models, i.e. pseudo-first-order, and pseudo-second- -order were used (Cai et al. 2015). The empirical formula of the used isotherm models is shown in Table 4.

\section{Results and discussion}

\section{Characterization of adsorbent}

Properties and morphology of AC and AC/NZVI were determined with a scanning electron microscope (SEM) and EDS analysis with an operating voltage of $20 \mathrm{keV}$. The image magnification electron is 9000 times. These analyses demonstrate the quantitative characteristics such as the particle size, shape/morphology and surface area of the adsorbents. Fig. 3a shows that the AC is more spherical and these spherical particles have hole-like structures. This property makes specific surfaces and increased reactivity highly available. From Fig. 3b, it can be seen that the size of NZVI ranged from 20-50 nm. The NZVI particles were immobilized on the surface or inside the pores of AC. Obviously, the immobilization of NZVI using $\mathrm{AC}$ prevented their aggregation, which is beneficial to maintaining their high surface area and reactivity (Rappoport 2004).

Table 3. Empirical formulas of the applied isotherm models (Z.L. Yaneva et al. 2012, K. Foo and B. Hameed 2010)

\begin{tabular}{|c|c|c|c|}
\hline Isotherm models & Expression & plot & Equation \\
\hline Langmuir & $\frac{C_{e}}{q_{e}}=\left(\frac{1}{K_{L} q_{m}}\right)+\left(\frac{1}{q_{m}}\right) C_{e}$ & $\frac{\mathrm{C}_{\mathrm{e}}}{\mathrm{q}_{\mathrm{e}}} \mathrm{Vs}_{\mathrm{e}}$ & 6 \\
\hline Freundlich & $\ln q_{e}=\ln k_{F}+\frac{1}{n} \log C_{e}$ & Log q $\mathrm{Vs}_{\mathrm{e}} \log \mathrm{C}_{\mathrm{e}}$ & 7 \\
\hline
\end{tabular}

Table 4. Empirical formulas of the applied kinetic models

(H.-m. Cai et al. 2015, V. Vadivelan and K.V. Kumar 2005, K.-Y.A. Lin et al. 2016).

\begin{tabular}{|c|c|c|c|}
\hline Kinetic models & Expression & plot & Eequation \\
\hline pseudo-first-order & $\ln \left(q_{e}-q_{t}\right)=\log \left(q_{e}\right)-\frac{k_{1}}{2.303} t$ & $\log \left(\mathrm{q}_{\mathrm{e}}-\mathrm{q}_{\mathrm{t}}\right) \mathrm{Vst}$ & 8 \\
\hline pseudo-second-order & $\frac{1}{q_{t}}=\left(\frac{1}{k_{2} q_{e}{ }^{2}}\right)+\left(\frac{1}{q_{e}}\right) t$ & $\frac{\mathrm{t}}{\mathrm{q}_{\mathrm{t}}} \mathrm{Vs} \mathrm{t}$ & 9 \\
\hline
\end{tabular}

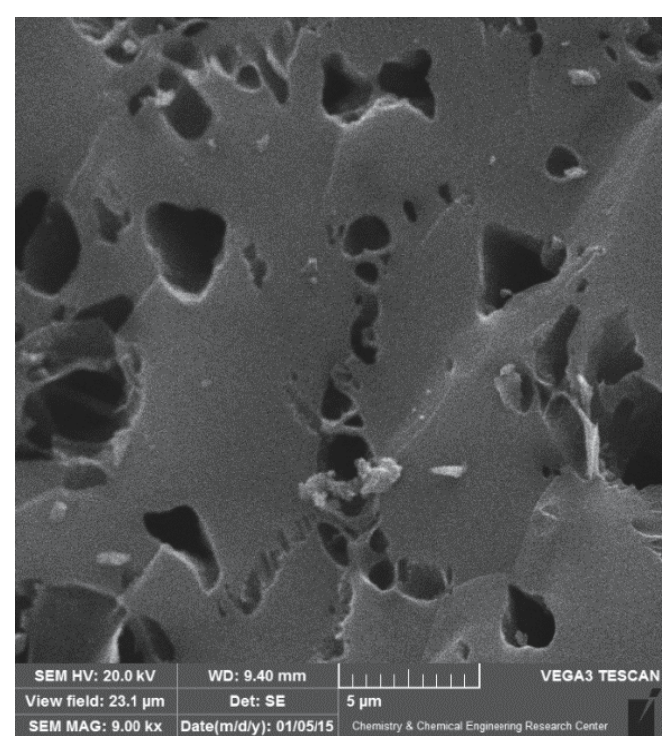

Fig. 3a. SEM image of AC

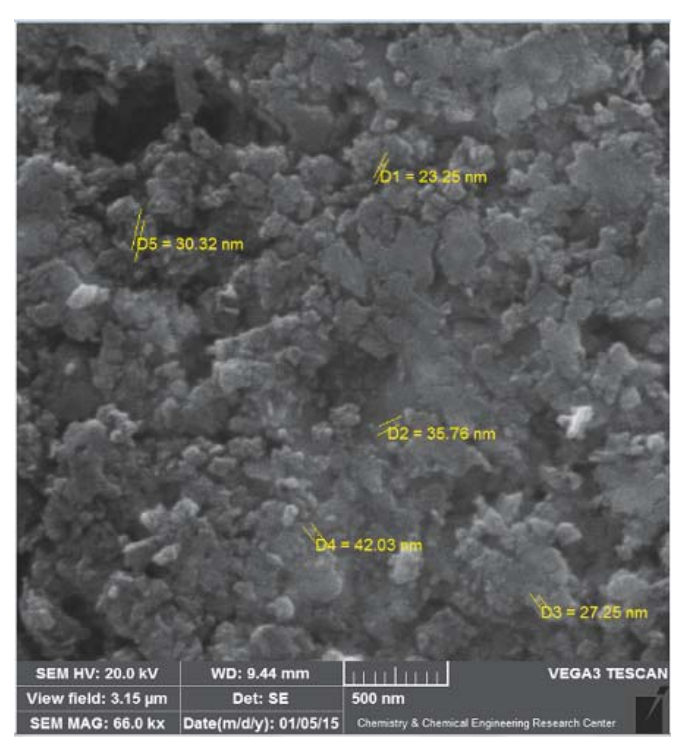

Fig. 3b. SEM image of NZVI/AC 
The results of the analysis of SEM-EDS (Fig. 4a and 4b) show the elemental analysis of AC and NZVI/AC. As Fig. 4a shows, the two main elements in the AC were carbon and oxygen ( 90.39 and 9.61 percent by weight, respectively). Fig. $4 \mathrm{~b}$ demonstrates that NZVI particles were distributed on the surface or loaded into the pores of AC. The Fe loaded on AC randomly. Furthermore, the presence of a Fe peak at $0.5 \mathrm{keV}$ in the EDS spectrum could be formed by $\mathrm{Fe}_{2} \mathrm{O}_{3}$ or $\mathrm{Fe}_{3} \mathrm{O}_{4}$. The oxide may appear because of the oxidation of $\mathrm{Fe}$ during the transfer and processing of the material for characterization. However, the peak at $0.5 \mathrm{keV}$ was weak, implying that most $\mathrm{Fe}$ element was present as $\mathrm{Fe}^{0}$. Consequently, it could also be deduced from the results that NZVI particles were successfully loaded onto AC and had preferable properties compared with non-supported particles.

The XRD diffraction patterns of $\mathrm{AC}$ and AC/NZVI are illustrated in Figs. 5a and 5b, respectively. In the pattern of $\mathrm{AC}$, there was only one broad peak at 24.14 corresponding to amorphous carbon (Rappoport 2004). The apparent peak at $2 \mathrm{~h}$ of 43.21 in AC/NZVI indicates the presence of $\mathrm{Fe}^{0}$. The wide angle XRD suggests that the iron species are dispersed, forming very small crystalline particles with sizes below the detection limit of X-ray diffraction. No characteristic diffraction peaks of $\mathrm{Fe}_{2} \mathrm{O}_{3}$ and $\mathrm{Fe}_{3} \mathrm{O}_{4}$ were detected, suggesting that the iron was mainly in its $\mathrm{Fe}^{0}$ state (Kanel et al. 2005).

\section{Model fitting and statistical analysis}

Table 1 shows that there was a considerable variation in the 4-CP removal by $\mathrm{AC}$ and $\mathrm{AC} / \mathrm{NZVI}$ at different values of selected parameters. A multiple regression analysis method was used for analyzing the data obtained based on Eq. (5). The predicted response $\mathrm{Y}$ for 4-CP removal was obtained. The final equation in terms of actual factors for $\mathrm{AC}$ and $\mathrm{AC} / \mathrm{NZVI}$ is given as:

Equation for $\mathrm{AC}$

$$
\begin{gathered}
\mathrm{Y}=29.05+(0.11 \times \text { concentration })+ \\
+(0.65 \times p H)+(1.43 \times \text { time })-(8.69 \times \text { dose })- \\
-(0.08 \times \text { concentration } \times p H)- \\
-(2.82 \times \text { concentration } \times \text { time })+ \\
+(0.13 \times \text { concentration } \times \text { dose })- \\
-(0.01 \times p H \times \text { time })+(1.85 \times p H \times \text { dose })+ \\
+\left(0.02 \times \text { time }^{\circ} \times \text { dose }\right)-\left(0.0008 \times \text { concentration }^{2}\right)- \\
-\left(0.28 \times p H^{2}\right)-\left(0.02 \times \text { time }^{2}\right)+\left(0.91 \times \text { dose }^{2}\right)
\end{gathered}
$$

Equation for NZVI/AC

$$
\begin{gathered}
\mathrm{Y}=70.51+(0.06 \times \text { concentration })+ \\
+(0.22 \times p H)+(1.58 \times \text { time })-(6.49 \times \text { dose })- \\
-(0.08 \times \text { concentration } \times p H)- \\
-(2.82 \times \text { concentration } \times \text { time })+ \\
+(0.13 \times \text { concentration } \times \text { dose })- \\
-(0.01 \times p H \times \text { time })+(1.84 \times p H \times \text { dose })+ \\
+\left(0.02 \times \text { time }^{\circ} \times \text { dose }\right)-\left(0.0008 \times \text { concentration }^{2}\right)- \\
-\left(0.28 \times p H^{2}\right)-\left(0.02 \times \text { time }^{2}\right)+\left(0.91 \times \text { dose }^{2}\right)
\end{gathered}
$$

The data obtained from Eq. (8) and (9) are significant. It is verified by $\mathrm{F}$ value and the analysis of variance (ANOVA)

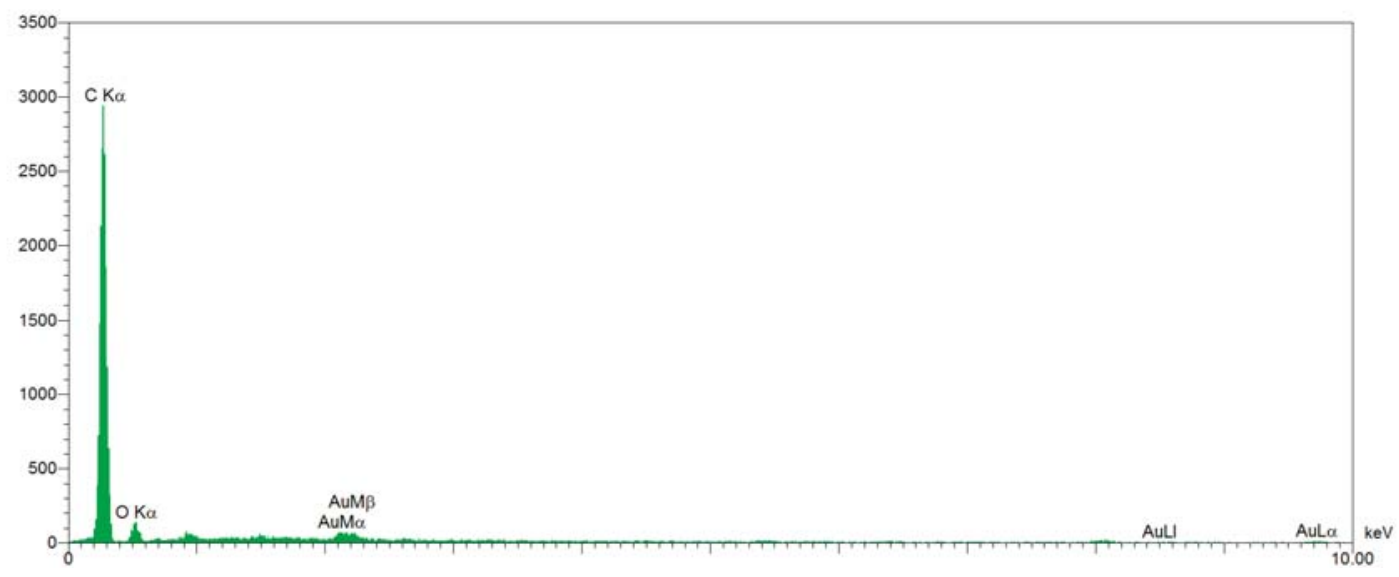

Fig. 4a. EDS diagrams of AC

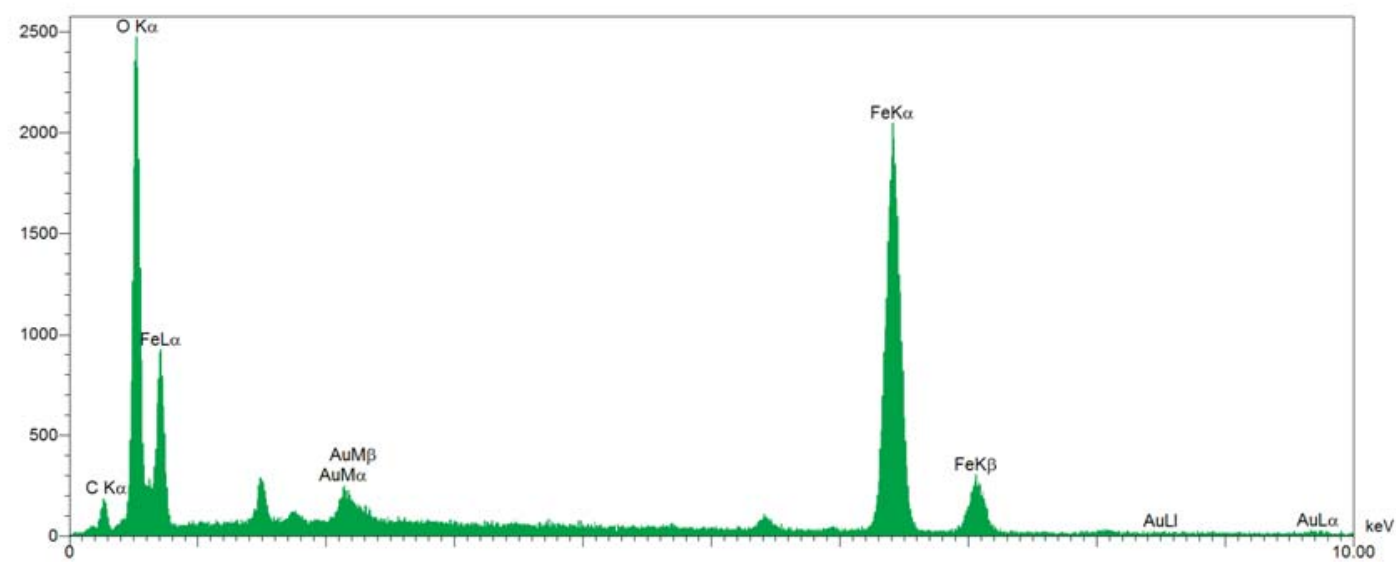

Fig. 4b. EDS diagrams of NZVI/AC 


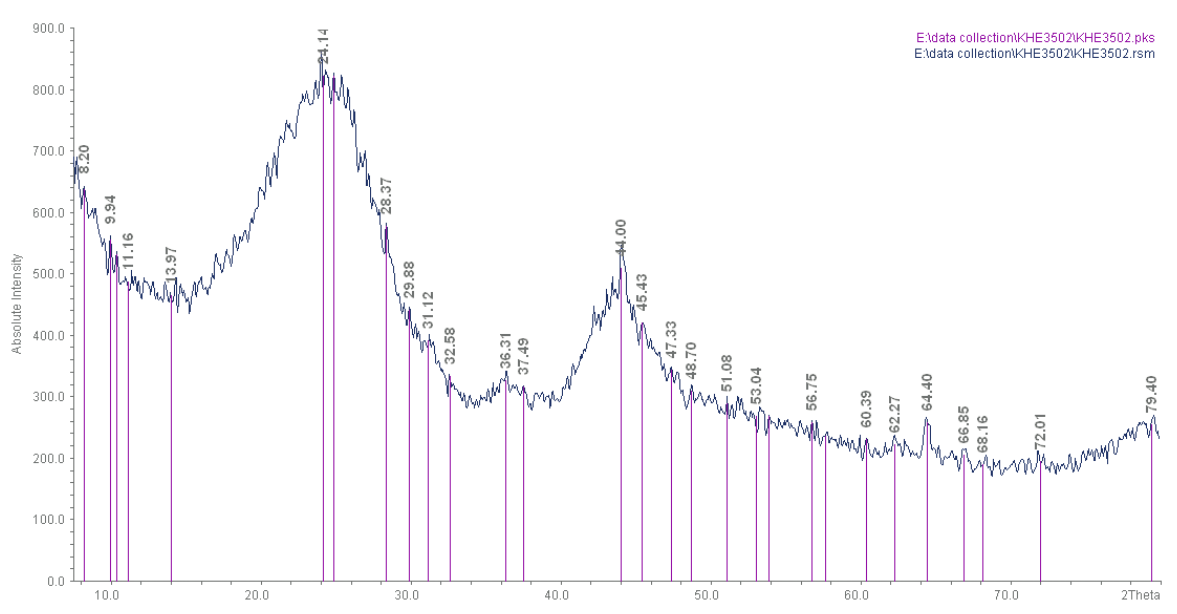

Fig. 5a. XRD patterns of $A C$

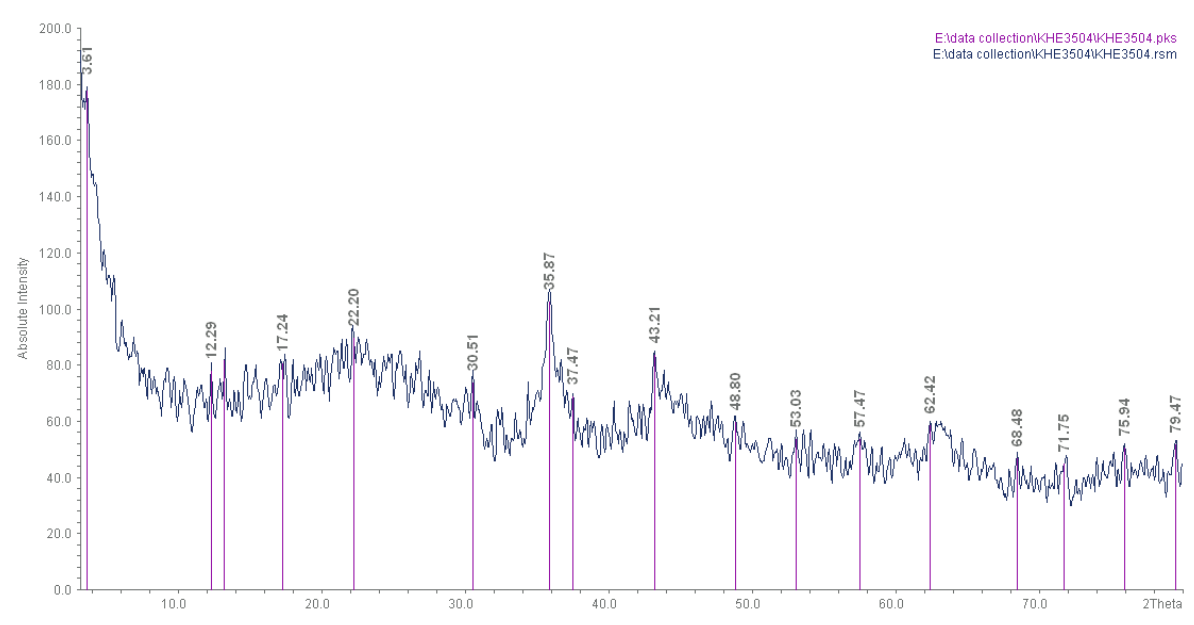

Fig. 5b. XRD patterns of NZVI/AC

by fitting the data of all independent variables in the response surface quadratic model. T-test, p-values, and sum of square (SS) were used to determine the significance of each coefficient of Eq. (8) and (9), which are listed in Table 2. The F-value is the test for comparing the model variance with residual (error) variance. If the variances are close to the same, the ratio will be close to one and it is less likely that any of the factors will have a significant effect on the response. It is the Mean Square for the term divided by the Mean Square for the Residual. The higher amount of F-value obtained, the more significant the model observed. The $\mathrm{p}$-values $<0.05$ were considered as significant. The SS parameter was similar to the F-value. As the SS increases, the more significant it would be. The Model F-value of 498.37 implies that the model is significant. There was only a $0.01 \%$ chance that a "Model F-Value" this large could occur due to noise. Values of "Prob > F" less than 0.05 indicate that the model terms are significant. In this case $\mathrm{X}_{1}$, $\mathrm{X}_{2}, \mathrm{X}_{3}, \mathrm{X}_{4}, \mathrm{X}_{5}, \mathrm{X}_{1} \mathrm{X}_{2}, \mathrm{X}_{1} \mathrm{X}_{4}, \mathrm{X}_{2} \mathrm{X}_{4}, \mathrm{X}_{2} \mathrm{X}_{5}, \mathrm{X}_{3} \mathrm{X}_{5}, \mathrm{X}_{2} 2, \mathrm{X}_{3} 2$ are significant model terms. Thus, ANOVA for response surface quadratic model gave F-value 498.37, p-value $<0.0001$ and SS 39954.15, implying that the model is significant for the removal of 4-cholorophenol.

The linear effect of coefficients 4-CP concentration $(\mathrm{p}<0.0001), \mathrm{pH}(\mathrm{p}<0.0001)$, contact time $(\mathrm{p}<0.0001)$, and adsorbent dose $(p<0.0001)$ is significant. Similarly, the interactive effects of concentration and $\mathrm{pH}(\mathrm{p}<0.0001)$, concentration and dose $(\mathrm{p}=0.049), \mathrm{pH}$ and dose $(\mathrm{p}=0.0005)$, $\mathrm{pH}$ and type of adsorbent $(\mathrm{p}=0.0037)$ and contact time and type of adsorbent $(\mathrm{p}<0.0001)$ are also significant, but the other interactive effects are insignificant. P-values of the quadratic terms, i.e., $\mathrm{pH}\left(\mathrm{X}_{2}^{2}\right) \quad(\mathrm{p}<0.0001)$, and contact time $\left(\mathrm{X}_{3}^{2}\right)$ $(\mathrm{p}<0.0001)$ are more significant.

To decide the adequacy of models among the varieties of models to represent 4-cholorophenol removal by AC/NZVI, we conducted research on the sequential model sum of squares and model summary statistics in our study, and the results are shown in Table 6. By focusing on the model maximizing the adjusted $R^{2}$ and the predicted $R^{2}$, we found the cubic model to be aliased. As well as that, the quadratic model was found to have maximum adjusted $R^{2}$ and the predicted $R^{2}$ values. The predicted $\mathrm{R}^{2}$ of 0.9881 was in reasonable agreement with the adjusted $\mathrm{R}^{2}$ of 0.9940 . Adequate precision measures the signal to noise ratio ( $\mathrm{S} / \mathrm{N}$ ratio). It compares the range of the predicted values at the design points to the average prediction error. Ratios greater than 4 demonstrate an adequate model discrimination and the $\mathrm{S} / \mathrm{N}$ ratio of 77.517 shows an adequate signal. This model can be applied to navigate the design space.

\section{The effect of the 4-CP concentration and $\mathrm{pH}$}

Response surface contour plots play a very important role in our understanding of the relationship between the response and 
experimental levels; they show the type of interaction between test variables and help to obtain the optimum conditions (Myers et al. 2016). Figure 6 shows 4-CP removal as a result of the interaction between the concentration and $\mathrm{pH}$. The initial concentration was 5,25 and $50 \mathrm{mg} / \mathrm{L}$. The points on the corners and center of the figure represent experimental design points. The point with number 6 in the center indicates that contour plots have been drawn when the value of the fixed variable is at the midpoint of the lowest and highest selected levels. Colors for the contour plots represent the removal efficiency. For example, red means the maximum removal, green medium and blue minimum removal efficiency. For both adsorbents, as 4-CP concentration increased, so the removal efficiency decreased. The results show that, with an increase in concentration, these organic contaminant molecules can be adsorbed on the surface of adsorbents and these ions can occupy a greater number of active sites on the particle surface (Babuponnusami and Muthukumar 2012). As a result, at lower concentration, a large number of pores on the sorbent surface was available for reaction. Generally, the initial concentration of pollutants is a major factor for the productivity of the adsorbent.

Furthermore, aqueous contaminants can be removed by ZVI through the reductive dechlorination of chlorinated solvents, or reduction of aqueous metal ions to an insoluble form. The following equation shows iron redox reactions with water and dissolved oxygen ( Ponder et al. 2000):

$$
2 \mathrm{Fe}^{0}+\mathrm{O}_{2}+2 \mathrm{H}_{2} \mathrm{O} \rightarrow 2 \mathrm{Fe}^{2+}+4 \mathrm{OH}^{-}
$$

As shown in Equation 13, $\mathrm{Fe}^{0}$ oxidation and the subsequent organic contaminant reduction indicate the degradation processes:

$$
R X+\mathrm{Fe}^{0}+H^{+} \leftrightarrow R H+\mathrm{Fe}^{2+}+X^{-}
$$

The surface area of a ZVI particle is an important rate parameter, at which all these analytes are remediated in a way that increasing the iron surface area would lead to the remediation rate enhancement (Ponder et al. 2000).

Table 5. Analysis of variance (ANOVA), regression coefficient estimate and test of significance for 4-CP removal

\begin{tabular}{|c|c|c|c|c|c|c|}
\hline Factor & $\begin{array}{c}\text { Sum of } \\
\text { squares }\end{array}$ & $\begin{array}{c}\text { Mean } \\
\text { squares }\end{array}$ & Coefficient estimated_S.E & d.f. & F-value & Probability $(p)>F$ \\
\hline Intercept (Model) & 39954.15 & 0.55 & $67.39 \pm 0.59$ & 19 & 498.37 & $<0.0001$ \\
\hline $\mathrm{X}_{1}$ & 1243.87 & 1243.87 & $-7.20 \pm 0.42$ & 1 & 294.79 .25 & $<0.0001$ \\
\hline $\mathrm{X}_{2}$ & 3316.56 & 3316.56 & $-11.76 \pm 0.42$ & 1 & 786.02 & $<0.0001$ \\
\hline$X_{3}$ & 5873.45 & 5873.45 & $15.64 \pm 0.42$ & 1 & 1391.99 & $<0.0001$ \\
\hline$X_{4}$ & 540.36 & 540.36 & $4.57 \pm 0.42$ & 1 & 128.06 & $<0.0001$ \\
\hline$X_{5}$ & 25982.95 & 25982.95 & $20.81 \pm 0.27$ & 1 & 6157.90 & $<0.0001$ \\
\hline $\mathrm{X}_{1} \mathrm{X}_{2}$ & 244.54 & 244.54 & $-5.53 \pm 0.73$ & 1 & 57.95 & $<0.0001$ \\
\hline $\mathrm{X}_{1} \mathrm{X}_{3}$ & 0.003 & 0.003 & $-0.019 \pm 0.73$ & 1 & 0.0007 & 0.0795 \\
\hline$X_{1} X_{4}$ & 17.40 & 17.40 & $1.48 \pm 0.73$ & 1 & 4.12 & 0.0493 \\
\hline$X_{1} X_{5}$ & 8.17 & 8.17 & $-0.58 \pm 0.42$ & 1 & 1.94 & 0.1723 \\
\hline $\mathrm{X}_{2} \mathrm{X}_{3}$ & 7.16 & 7.16 & $-0.95 \pm 0.73$ & 1 & 1.70 & 0.2004 \\
\hline $\mathrm{X}_{2} \mathrm{X}_{4}$ & 60.67 & 60.67 & $2.75 \pm 0.73$ & 1 & 14.38 & 0.0005 \\
\hline $\mathrm{X}_{2} \mathrm{X}_{5}$ & 40.48 & 40.48 & $-1.30 \pm 0.42$ & 1 & 9.59 & 0.0037 \\
\hline $\mathrm{X}_{3} \mathrm{X}_{4}$ & 0.78 & 0.78 & $0.31 \pm 0.73$ & 1 & 0.18 & 0.6707 \\
\hline $\mathrm{X}_{3} \mathrm{X}_{5}$ & 117.53 & 117.53 & $2.21 \pm 0.42$ & 1 & 27.85 & $<0.0001$ \\
\hline$X_{4} X_{5}$ & 7.26 & 7.26 & $0.55 \pm 0.42$ & 1 & 1.72 & 0.1975 \\
\hline $\mathrm{X}_{1}^{2}$ & 2.48 & 2.48 & $-0.42 \pm 0.55$ & 1 & 0.59 & 0.4481 \\
\hline $\mathrm{X}_{2}^{2}$ & 88.80 & 88.80 & $-2.54 \pm 0.55$ & 1 & 21.05 & $<0.0001$ \\
\hline $\mathrm{X}_{3}{ }^{2}$ & 2393.95 & 2393.95 & $-13.21 \pm 0.55$ & 1 & 567.36 & $<0.0001$ \\
\hline $\mathrm{X}_{4}^{2}$ & 0.71 & 0.71 & $0.23 \pm 0.55$ & 1 & 0.17 & 0.6843 \\
\hline Residual & 160.34 & 4.22 & & 38 & & \\
\hline Corrected total & 40115.60 & & & 59 & & \\
\hline
\end{tabular}
(response surface quadratic model)

\begin{tabular}{|c|c|c|c|c|c|c|}
\hline Source & $\begin{array}{l}\text { Std. } \\
\text { Dev. }\end{array}$ & R-Squared & $\begin{array}{c}\text { Adjusted } \\
\text { R-Squared }\end{array}$ & $\begin{array}{l}\text { Predicted } \\
\text { R-Squared }\end{array}$ & PRESS & \\
\hline Linear & 7.79 & 0.9213 & 0.9137 & 0.8940 & 4253.36 & \\
\hline $2 \mathrm{FI}$ & 7.95 & 0.9339 & 0.9102 & 0.8551 & 5811.70 & \\
\hline Quadratic & 2.05 & 0.9960 & 0.9940 & 0.9881 & 476.26 & Suggested \\
\hline Cubic & 1.31 & 0.9991 & 0.9976 & 0.9820 & 723.63 & Aliased \\
\hline
\end{tabular}

Table 6. Model Summary Statistics 
The contact between the organic contaminant and reactive site on the iron nanoparticle surface directly determines 4-CP removal by the nanoparticle. 4-CP was adsorbed on the reactive iron particle surface after being spread through the solution. Then, iron nanoparticles as electron donors were corroded following the occurrence of an effective contact between them and molecular 4-CP (Moradi et al. 2016). In addition, hydrogen peroxide could be created by iron corrosion in the presence of oxygen. As a result, strong oxidants like $\mathrm{OH} \bullet$ species could be produced by the reaction between $\mathrm{Fe}^{2}$ and hydrogen peroxide (Moradi et al. 2016). The 4-CP bond was broken by the organic pollutant degradation with help of the hydroxyl radical as soon as the 4-CP was adsorbed onto the nanoparticle surface (Fig. 6).

As previously shown by Teseng et al., the 4-CP accumulated around ZVI inside the pores on the AC surface was attracted by the AC adsorption after treating 4-CP with the AC-NZVI composites. Then, both the sorbed and dissolved 4-CP were degraded after 4-CP dechlorination by NZVI, which led to a zero-order $\mathrm{Cl}$ liberation reaction. The AC-NZVI composites as a reactive $\mathrm{AC}$ could be used to combine the destructive reactivity of NZVI dechlorination with the GAC physical adsorption capacity, thus avoiding the limitations of using them separately (Tseng et al. 2011).
As the results demonstrated, acidic conditions were more suitable for the removal of 4-CP. So that the highest removal efficiency was observed in acidic $\mathrm{pH}$ for both adsorbent, and when $\mathrm{pH}$ was greater than 6 , the removal efficiency decreased. At acidic $\mathrm{pH}$, the concentration of $\mathrm{H}^{+}$ions increases and the surface of the adsorbent has a positive charge by absorption of the protons. On the other hand, 4-CP is an anionic compound and most of these contaminants were reduced effectively at lower $\mathrm{pH}$ values (Zhang et al. 2007). So, it can help the adsorption of 4-CP on the adsorbent.

At alkaline condition, a low generation of $\mathrm{H}_{2}$ blocked the degradation of 4-CP and ferrous hydroxide precipitates also produced an inactive layer on the ZVI particle surface. These layers cover the reactive sites and make these nanoparticles ineffective. In addition, adsorbents can adsorb hydroxide groups to make them negatively charged. Thus, the weak interaction or even electrostatic repulsive force between the contaminant and the adsorbent will be created, which thereby retards diffusion and adsorption and, consequently, reduces the removal efficiency.

As shown in Figures $7 \mathrm{a}$, and $7 \mathrm{~b}$, the maximum efficiency of 4-CP occurred at a concentration of about 5 and a $\mathrm{pH}$ of nearly 3 . The efficiency was $53.68 \%$ and $97.23 \%$ for AC and AC/NZVI, respectively.

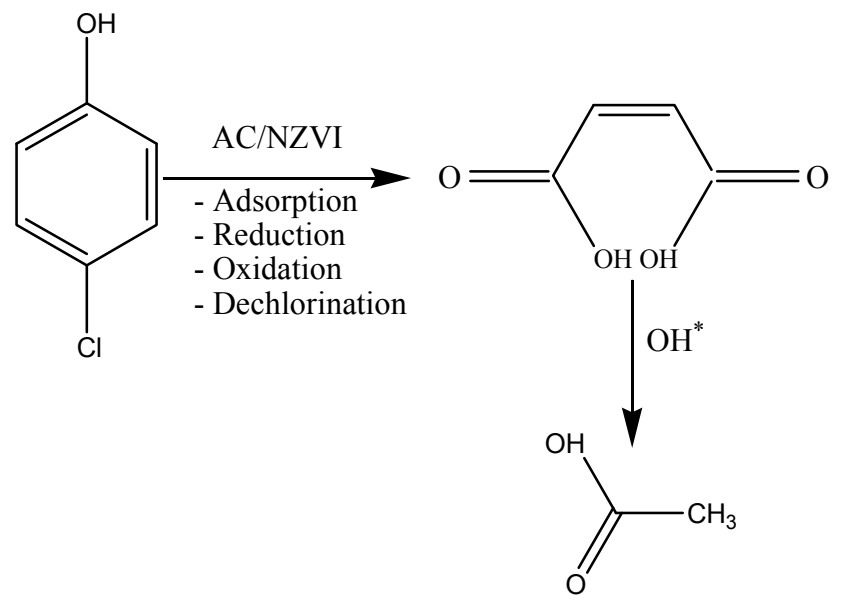

Fig. 6. 4-chlorophenol degradation in the presence of AC/NZVI

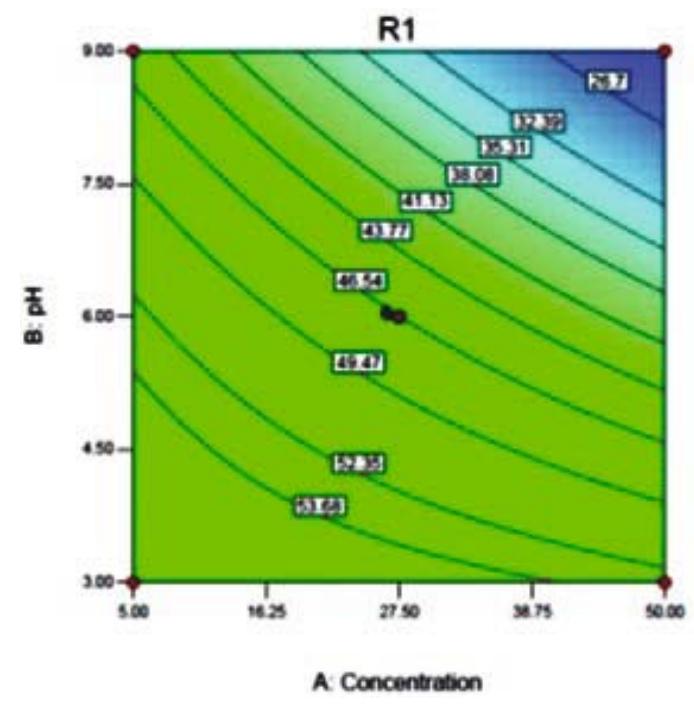

Fig. 7a. Response surface contour plots showing effect of concentration and $\mathrm{pH}$ on $4-\mathrm{CP}$ removal (\%) by AC

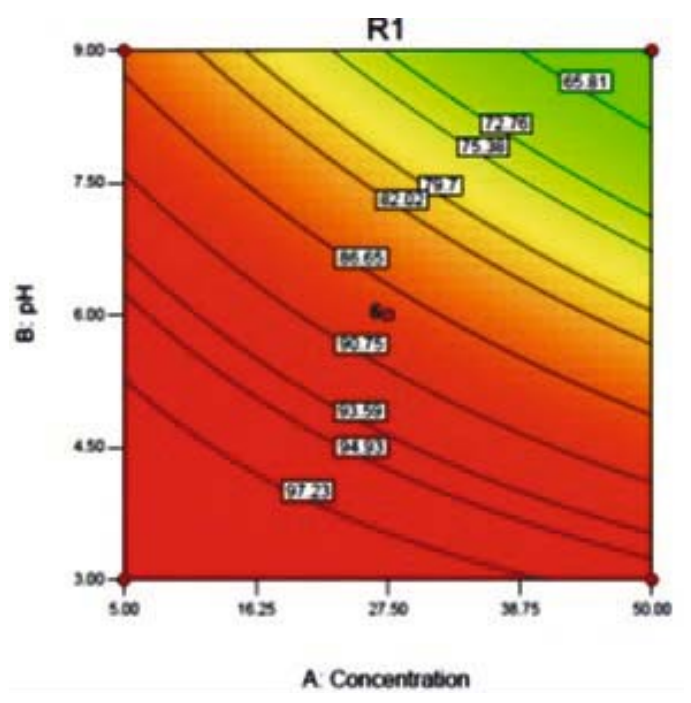

Fig. 7b. Response surface contour plots showing effect of concentration and $\mathrm{pH}$ on $4-\mathrm{CP}$ removal (\%) by NZVI/AC 


\section{The effect of contact time and AC/NZVI dosage}

As can be seen in Figures $7 \mathrm{a}$ and $7 \mathrm{~b}$, by increasing the contact time from 1 to $60 \mathrm{~min}$, efficiency was increased in all doses, however, by increasing the contact time from 30 to $60 \mathrm{~min}$, efficiency was increased in the form of a minor because the plot slope was reduced. This shows that, in the first stages of absorption, a large number of binding sites are available for adsorption of 4-CP.

However, over time, due to the accumulation of pollutants on the surface of the adsorbent and repulsive forces between adsorbed molecules on a solid surface, as well as molecules in solution phase, the rate of absorption is reduced. As a result of this incident, the adsorbent is saturated and cannot absorb any more pollutants. Therefore, in order to create economic conditions and a reduction in energy consumption, the contact time of 30 minutes was selected as the optimum time (Tseng et al. 2011, Cheng et al. 2005).

\section{Optimization and model validation}

The main objective of the optimization is to determine the optimum values of variables for 4-CP removal efficiency. In optimization, the desired aim in terms of the 4-CP removal efficiency was defined as a target to achieve maximum removal efficiency.

Despite $\mathrm{AC}$ at optimum concentration (5 mg 4-CP/L), $\mathrm{pH}$ (4.43), contact time (46.28 $\mathrm{min})$, and dose (1.5 g AC/L), the model predicted $60 \%$ removal efficiency, for AC/NZVI at optimum concentration (5.48 mg 4-CP/L), $\mathrm{pH}$ (5.44), contact time $(44.7 \mathrm{~min})$, and dose $(0.65 \mathrm{~g} / \mathrm{L})$ the model predicted $100 \%$ removal efficiency.

\section{Adsorption kinetic study}

To investigate the factor influencing the reaction rate, it is essential to study the kinetics of the process. Adsorption kinetics were studied in order to better understand the adsorption dynamic of 4-CP on the adsorbent and to produce a predictive model to estimate the amount of ions absorbed during the process provided. Figures $9 \mathrm{a}$ and $9 \mathrm{~b}$ show pseudo-first-order and pseudo-second-order kinetics curves, respectively. $\mathrm{R}^{2}$ obtained for the first pseudo-models for AC and AC/NZVI were 0.5424 and 0.9164 , respectively. $\mathrm{R}^{2}$ obtained for the second pseudo-models were 0.9999 and 0.9996 , respectively. Therefore, the pseudo-second kinetic model is more acceptable for analysis of 4-CP on both adsorbents. Even though the

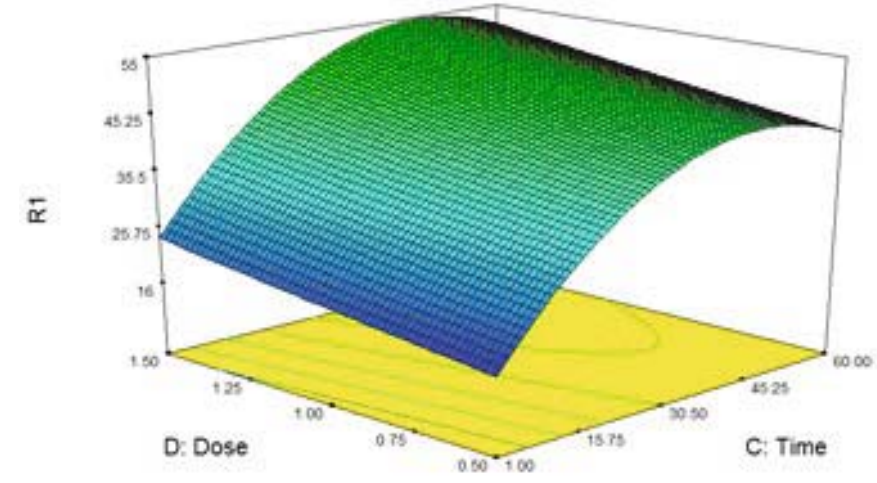

Fig. 8a. Response surface 3D plots showing effect of contact time and dose on 4-CP removal (\%) by AC pseudo-first order kinetic model is based on adsorbent capacity and is applied when adsorption using a diffusion mechanism occurs within a boundary layer, the pseudo-second order kinetic model shows that chemical adsorption is the dominant and controlling mechanism in the process of adsorption (Lin et al. 2016).

\section{Studying adsorption isotherms}

Adsorption isotherms describe the mass-transfer equilibrium between a reservoir and a surface, on which molecules can be adsorbed (Foo and Hameed 2010, Ciobanu et al. 2016). In order to determine the adsorption capacity of adsorbent and to examine the mechanisms of adsorption, isotherm models were used. The 4-CP sorption studies onto AC/NZVIe were investigated by changing the initial adsorbent concentrations ranging from 1 to $50 \mathrm{mg} \mathrm{L}^{-1}$. In order to evaluate the experimental results and the performance of adsorption Langmuir, Freundlich models were utilized. The calculated isotherm parameters of the two models are summarized in Table 7. As it is clear from the results and determination coefficient, the Langmuir isotherm model is able to better explain the test results for $\mathrm{AC}\left(\mathrm{R}^{2}=0.9911\right)$ and AC/NZVI $\left(\mathrm{R}^{2}=0.9939\right)$. This means that the 4-CP adsorption could be attributed to homogeneous surface active sites of AC/NZVIe and it is possible that adsorption takes place in a monolayer adsorption manner. The Langmuir isotherm model describes the monolayer adsorption of the adsorbate on a homogeneous adsorbent surface. According to the Langmuir model, the maximum capacity of AC/NZVI for 4-CP is $46.1 \mathrm{mg} \mathrm{g}^{-1}$. For the 4-chlorophenol and dye to be quickly adsorbed, carbon activation from $\mathrm{H} 2 \mathrm{SO} 4$-pretreated corncob hulls were studied to occur through $\mathrm{KOH}$ activation (Wu et al. 2011) and $\mathrm{q}_{\max }$ of 5.53 was obtained. Thus, a faster adsorption of 4-CP on AC/NZVI with a higher $\mathrm{q}_{\max }$ was found to be caused by the present adsorbent compared to those reported by $\mathrm{Wu}$.

\section{Conclusion}

To sum up, activated carbon modified with nano zero-valent iron appears effective in removal of 4-CP. The coupling of AC with NZVI induced a synergistic process which allowed for a maximum removal of 4-CP thus providing the feasibility of this adsorbent. The linear effect of coefficients 4-CP concentration, $\mathrm{pH}$, contact time, and adsorbent dose is significant $(\mathrm{p}<0.0001)$. Similarly, the interactive effects of concentration and $\mathrm{pH}$,

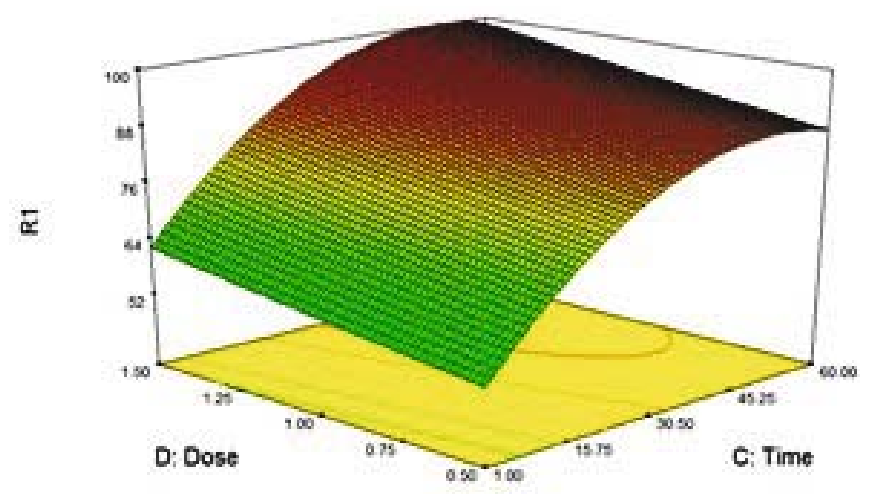

Fig. 8b. Response surface 3D plots showing effect of contact time and dose on 4-CP removal (\%) by NZVI/AC 


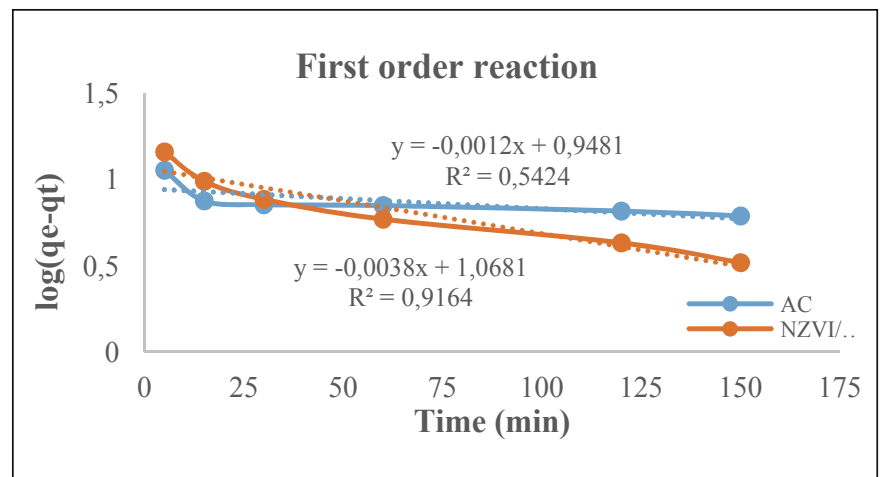

Fig. 9a. First order reaction of 4-CP absorption on $\mathrm{AC}$ and $\mathrm{NZVI} / \mathrm{AC}$ (concentration= $25 \mathrm{mg} / \mathrm{L}, \mathrm{pH}=6-7.5, \mathrm{~T}=25^{\circ} \mathrm{C}$ )

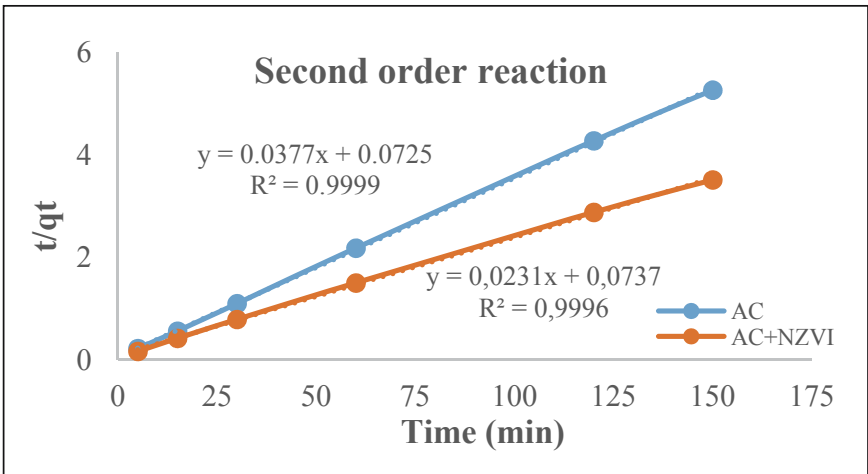

Fig. 9b. Freundlich model of 4-CP absorption on AC and NZVI/AC (concentration= $25 \mathrm{mg} / \mathrm{L}, \mathrm{pH}=6-7.5, \mathrm{~T}=25^{\circ} \mathrm{C}$ )

Table 7. The value of parameters for used adsorption isotherm models

\begin{tabular}{|c|c|c|c|c|c|c|}
\hline \multirow{2}{*}{ Adsorbent } & \multicolumn{3}{|c|}{ Langmuir } & \multicolumn{3}{c|}{ Freundlich } \\
\cline { 2 - 7 } & $\mathbf{K}_{\mathbf{L}}$ & $\mathbf{q}_{\mathbf{m}}$ & $\mathbf{R}^{2}$ & $\mathbf{k}_{\mathbf{f}}$ & $\mathbf{n}$ & $\mathbf{R}^{2}$ \\
\hline AC & -6.0786 & 34.7 & 0.9903 & 0.1551 & 0.7131 & 0.9376 \\
\hline NZVI/AC & -3.7419 & 46.1 & 0.9938 & 1.3158 & 0.6176 & 0.9384 \\
\hline
\end{tabular}

concentration and dose, $\mathrm{pH}$ and dose, $\mathrm{pH}$ and type of adsorbent and contact time and type of adsorbent are also significant $(p<0.05)$. Analysis of variance (ANOVA) for response surface quadratic model shows that the experiments are highly accurate and the model is highly significant. In addition, this shows the excellent degree of fitness for the model equation.

\section{Acknowledgement}

The authors are most thankful to the laboratory staff of the Department of Environmental Health Engineering, School of Public Health, Shahid Beheshti University of Medical Sciences for the financial support and their collaboration in this study.

\section{References}

Akar, T., Ozcan, A. S., Tunali, S. \& Ozcan, A. (2008). Biosorption of a textile dye (Acid Blue 40) by cone biomass of Thuja orientalis: Estimation of equilibrium, thermodynamic and kinetic parameters, Bioresource Technology, 99, 8, pp. 3057-3065.

Asghar, A., Abdul Raman, A.A. \& Daud, W.M.A.W. (2014). A comparison of central composite design and Taguchi method for optimizing Fenton process, The Scientific World Journal, vol. 2014, pp. 1-14.

Babuponnusami, A. \& Muthukumar, K. (2012). Removal of phenol by heterogenous photo electro Fenton-like process using nano-zero valent iron, Separation and Purification Technology, 98, pp. 130-135.

Bayramoğlu, G. \& Arıca, M.Y. (2008). Enzymatic removal of phenol and p-chlorophenol in enzyme reactor: Horseradish peroxidase immobilized on magnetic beads, Journal of Hazardous Materials, 156, 1-3, pp. 148-155.

Bayramoglu, G., Gursel, I., Tunali, Y. \& Arica, M.Y. (2009). Biosorption of phenol and 2-chlorophenol by Funaliatrogii pellets, Bioresource Technology, 100, 10, pp. 2685-2691.

Cai, H.-M., Chen, G.-J., Peng, C.-Y., Zhang, Z.-Z., Dong, Y.-Y., Shang, G.-Z., Zhu, X.-H., Gao, H.-J. \& Wan, X.-C. (2015).
Removal of fluoride from drinking water using tea waste loaded with Al/Fe oxides: A novel, safe and efficient biosorbent, Applied Surface Science, 328, pp. 34-44.

Cheng, W., Dastgheib, S.A. \& Karanfil, T. (2005). Adsorption of dissolved natural organic matter by modified activated carbons, Water Research, 39, 11, pp. 2281-2290.

Choe, S., Lee, S.-H., Chang, Y.-Y., Hwang, K.-Y. \& Khim, J. (2001). Rapid reductive destruction of hazardous organic compounds by nanoscale Fe0, Chemosphere, 42, 4, pp. 367-372.

Ciobanu, G., Barna, S. \& Harja, M. (2016). Kinetic and equilibrium studies on adsorption of Reactive Blue 19 dye from aqueous solutions by nanohydroxyapatite adsorbent, Archives of Environmental Protection, 42, 2, pp. 3-11.

Doddapaneni, K.K., Tatineni, R., Potumarthi, R. \& Mangamoori, L.N. (2007). Optimization of media constituents through response surface methodology for improved production of alkaline proteases by Serratia rubidaea, Journal of Chemical Technology and Biotechnology, 82, 8, pp. 721-729.

Eckenfelder, W.W. (1989). Industrial water pollution control, McGraw-Hill, 1989.

Fakhri, A. (2015). Investigation of mercury (II) adsorption from aqueous solution onto copper oxide nanoparticles: optimization using response surface methodology, Process Safety and Environmental Protection, 93, pp. 1-8.

Foo, K. \& Hameed, B. (2010). Insights into the modeling of adsorption isotherm systems, Chemical Engineering Journal, 156, 1, pp. 2-10.

Handbook, E. (1998). Advanced Photochemical Oxidation Processes, Office of Research and Development Washington, DC, 20460.

Jafari, A., Mahvi, A. H., Godini, H., Rezaee, R. \& Hosseini, S.S. (2014). Process optimization for fluoride removal from water by Moringa Oleifera seed extract, Fluoride, 47, pp. 152-160.

Joo, S.H., Feitz, A.J. \& Waite, T.D. (2004). Oxidative degradation of the carbothioate herbicide, molinate, using nanoscale zero-valent iron, Environmental Science \& Technology, 38, 7, pp. 2242-2247.

Kanel, S.R., Manning, B., Charlet, L. \& Choi, H. (2005). Removal of arsenic (III) from groundwater by nanoscale zero-valent iron, Environmental Science \& Technology, 39, 5, 1291-1298. 
Kassaee, M.Z., Motamedi, E., Mikhak, A. \& Rahnemaie, R. (2011). Nitrate removal from water using iron nanoparticles produced by arc discharge vs. reduction, Chemical Engineering Journal, 166, 2, pp. 490-495.

Lai, C. \& Chen, C.-Y. (2001). Removal of metal ions and humic acid from water by iron-coated filter media, Chemosphere, 44, 5, pp. 1177-1184.

Lin, K.-Y. A., Liu, Y.-T. \& Chen, S.-Y. (2016). Adsorption of fluoride to UiO-66-NH2 in water: stability, kinetic, isotherm and thermodynamic studies, Journal of Colloid And Interface Science, 461, pp. 79-87.

Mangal, H., Saxena, A., Rawat, A.S., Kumar, V., Rai, P.K. \& Datta, M. (2013). Adsorption of nitrobenzene on zero valent iron loaded metal oxide nanoparticles under static conditions, Microporous and Mesoporous Materials, 168, pp. 247-256.

Michaux, F., Carteret, C., Stébé, M.-J. \& Blin, J.-L. (2013). Investigation of properties of mesoporous silica materials based on nonionic fluorinated surfactant using Box-Behnken experimental designs, Microporous and Mesoporous Materials, 174, pp. 135-143.

Moradi, M., Fazlzadehdavil, M., Pirsaheb, M., Mansouri, Y., Khosravi, T. \& Sharafi, K. (2016). Response surface methodology (RSM) and its application for optimization of ammonium ions removal from aqueous solutions by pumice as a natural and low cost adsorbent, Archives of Environmental Protection, 42, 2, pp. 33-43.

Mourabet, M., El Rhilassi, A., El Boujaady, H., Bennani-Ziatni, M., El Hamri, R. \& Taitai, A. (2012). Removal of fluoride from aqueous solution by adsorption on Apatitic tricalcium phosphate using Box-Behnken design and desirability function, Applied Surface Science, 258, 10, pp. 4402-4410.

Myers, R.H., Montgomery, D.C. \& Anderson-Cook, C.M. (2016). Response surface methodology: process and product optimization using designed experiments, John Wiley \& Sons, 2016.

Navarro, A.E., Portales, R.F., Sun-Kou, M.R. \& Llanos, B.P. (2008). Effect of $\mathrm{pH}$ on phenol biosorption by marine seaweeds, Journal of Hazardous Materials, 156, 1-3, pp. 405-411.

Ponder, S.M., Darab, J.G. \& Mallouk, T.E. (2000). Remediation of $\mathrm{Cr}$ (VI) and $\mathrm{Pb}$ (II) aqueous solutions using supported, nanoscale zero-valent iron, Environmental Science \& Technology, 34, 12, pp. 2564-2569.

Qin, Q., Wang, Q., Fu, D. \& Ma, J. (2011). An efficient approach for $\mathrm{Pb}(\mathrm{II})$ and $\mathrm{Cd}(\mathrm{II})$ removal using manganese dioxide formed in situ, Chemical Engineering Journal, 172, 1, pp. 68-74.

Ra, J.S., Oh, S.-Y., Lee, B.C. \& Kim, S.D. (2008). The effect of suspended particles coated by humic acid on the toxicity of pharmaceuticals, estrogens, and phenolic compounds, Environment International, 34, 2, pp. 184-192.

Rappoport, Z. (2004). The Chemistry of Phenols, 2 Volume Set, John Wiley \& Sons, 2004.

Rice, E.W., Baird, R.B., Eaton, A.D. \& Clesceri, L.S. (2012). Standard methods for the examination of water and wastewater, American
Public Health Association, American Water Works Association, Water Environment Federation, 2012.

Rodríguez, M. (2003). Fenton and UV-vis based advanced oxidation processes in wastewater treatment: Degradation, mineralization and biodegradability enhancement, Universitat de Barcelona, 2003.

Sądej, W., Żołnowski, A.C. \& Marczuk, O. (2016). Content of phenolic compounds in soils originating from two long-term fertilization experiments, Archives of Environmental Protection, 42, 4, pp. 104-113.

Souza, A.S., Dos Santos, W.N. \& Ferreira, S.L. (2005). Application of Box-Behnken design in the optimisation of an on-line pre-concentration system using knotted reactor for cadmium determination by flame atomic absorption spectrometry, Spectrochimica Acta Part B: Atomic Spectroscopy, 60, 5, pp. 737-742.

Tepe, O. \& Dursun, A.Y. (2008). Combined effects of external mass transfer and biodegradation rates on removal of phenol by immobilized Ralstonia eutropha in a packed bed reactor, Journal of Hazardous Materials, 151, 1, pp. 9-16.

Tseng, H.-H., Su, J.-G. \& Liang, C. (2011). Synthesis of granular activated carbon/zero valent iron composites for simultaneous adsorption/dechlorination of trichloroethylene, Journal of Hazardous Materials, 192, 2, pp. 500-506.

Vadivelan, V. \& Kumar, K.V. (2005). Equilibrium, kinetics, mechanism, and process design for the sorption of methylene blue onto rice husk, Journal of Colloid And Interface Science, 286, 1, pp. 90-100.

W.H.O. 1989. Chlorophenols other than pentachlorophenol. Geneva: World Health Organization.

Wu, F.-C., Wu, P.-H., Tseng, R.-L. \& Juang, R.-S. (2011). Preparation of novel activated carbons from H2SO4-Pretreated corncob hulls with $\mathrm{KOH}$ activation for quick adsorption of dye and 4-chlorophenol, Journal of Environmental Management, 92, 3, pp. 708-713.

Wu, J. \& Yu, H.-Q. (2007). Biosorption of 2,4-dichlorophenol by immobilized white-rot fungus Phanerochaete chrysosporium from aqueous solutions, Bioresource Technology, 98, 2, pp. 253-259.

Yaneva, Z.L., Koumanova, B.K. \& Georgieva, N.V. (2012). Linear and nonlinear regression methods for equilibrium modelling of p-nitrophenol biosorption by Rhizopus oryzae: Comparison of error analysis criteria, Journal of Chemistry, 2013.

Yazdanbakhsh, A.R. \& Hashempour, Y. (2015). Experimental design and response surface modeling for optimization of humic substances removal by activated carbon: A kinetic and isotherm study, Journal of Advances in Environmental Health Research, 3, 2, pp. 91-101.

Zhang, W.-H., Quan, X. \& Zhang, Z.-Y. (2007). Catalytic reductive dechlorination of $\mathrm{p}$-chlorophenol in water using $\mathrm{Ni} / \mathrm{Fe}$ nanoscale particles, Journal of Environmental Sciences, 19, 3, pp. 362-366. 